\title{
Competition and Market Power in Physician Private PRACTICES
}

\author{
TIMOTHY S. GUNNING \\ James A. BAKER III Institute for Public Policy \\ RICE UNIVERSITY \\ 6100 MAIN STREET SOUTH \\ Houston, TX 77005 \\ Robin C. SICKLES * \\ RICE UNIVERSITY \\ DEPARTMENT OF ECONOMICS \\ 6100 MAIN STREET SOUTH \\ HOUSTON, TX 77005
}

\begin{abstract}
This paper presents a theoretical and empirical model for analyzing competition in physician private practices using a conjectural variation framework. Our study uses the 1998 American Medical Association (AMA) Socioeconomic Monitoring Survey (SMS) to isolate the marginal cost of physician services at the physician practice level and tests for the degree of collusion and market power in physician private practices. The year 1998 is of particular interest due to charges filed in federal court by The United States Department of Justice (DOJ) against a variety of large physician practices, consequently ruling that physicians could no longer engage in joint negotiations. We investigate the grounds for the indictment by the DOJ, which was based primarily on anecdotal economic and legal observations, rather than the results of empirical evidence from accepted econometric modeling. Our results reveal that the behavior of physicians in medical subspecialties and surgical subspecialties is consistent with a Cournot oligopoly.
\end{abstract}

Keywords: physician, multi-product cost function, competition, conjectural variation JEL: C30, D24, I12, L13

${ }^{*}$ Corresponding author, telephone: 1-713-348-3322, e-mail: rsickles@rice.edu 
"The long-term fiscal condition of the United States has been largely misdiagnosed. Despite the attention paid to demographic challenges, such as the coming retirement of the baby-boom generation, our country's financial health will in fact be determined primarily by the growth rate of per capita healthcare costs"

-P. Ellis and P. Orszag ${ }^{1}$ (November, 2007)

\section{INTRODUCTION}

The cost of healthcare is at the forefront of virtually every presidential debate, policy discussion, and empirical analysis on medical markets. The federal government alone will spend in excess of $\$ 560$ billion on the its two healthcare programs, Medicare and Medicaid, accounting for roughly $20 \%$ of all federal spending and $5 \%$ of gross domestic product. Perhaps the most astonishing estimates are the aggregate projections based on per enrollee figures. The Congressional Budget Offices (CBO) estimates that if the current per enrollee spending trend should continue, the cost of the two federal programs in the year 2050 would exceed $20 \%$ of the nation's gross domestic product. ${ }^{2}$ Private insurance companies face similar strains and are often forced to realign fee schedules.

From a government perspective there are a number of theories that address the potential sources of the increased spending. The $\mathrm{CBO}$ cites rising illness rates in metropolitan regions and the increasing demand for funds that properly treat the poor population, alleging that few of those funds are being used for preventative care. Meanwhile, the 2008 budget proposal from the Bush Administration suggests cutting the resources of Medicare in an attempt to eliminate the inefficiencies and overspending of the system. The opposition to the Administration argues that healthcare funding should be increased to offset the anticipated health-related expenses in future generations.

\footnotetext{
${ }^{1}$ Director of the Congressional Budget Office.

2 See CBO Testimony before the Committee on the Budget (U.S. House of Representatives), "Performance Budgeting: Applications to Health Insurance Programs and Tax Policy”, September 20, 2007.
} 
While the above arguments certainly provide much needed dialogue for a fiscal issue in a perpetual state of disarray, very little criticism has been directed to the structure of medical markets, in particular, the degree of inefficiency that may arise from varying forms of market power. Certainly, hospitals and physician private practices have considerable impact on national health. While the former has been studied at great length, the latter is also of interest.

Before one can examine the structure of the physician market, it is first essential to examine how physicians receive their rents. A large portion of Medicare and Medicaid tax revenues are paid directly to the physician. Physicians are reimbursed for their services by means of a geographic practice cost index (Zuckerman, et al. 1990) and a relative-value unit weighting schedule. The geographic price index (GPCI) is designed to adjust for price fluctuations by region, while the relative-value unit (RVU) weighting mechanism is used to quantify the relationship between specific practice-related characteristics. Meanwhile, private insurance companies reimburse physicians based on pre-negotiated rents. Economic theory suggests that reimbursements greatly exceeding marginal cost act as a deterrent for competitive practices and compromise the economic landscape.

In 1998 the Department of Justice (DOJ) brought action against a number of large physician practices, alleging that their cooperative efforts within- and between-networks led to Sherman antitrust violations. The primary conclusion reached by the DOJ is that physicians and physician groups do not have the authority to collude in negotiations with third-party payers. Prior to the investigation by the DOJ, most of the allegations were on behalf of private insurance companies who claimed that third-party payers do not have the power to negotiate a reasonable economic rent for service. ${ }^{3}$ This study investigates the

\footnotetext{
${ }^{3}$ See United States vs. Marshfield Clinic or United States vs. Federation of Physicians and Dentists, Inc.
} 
claims made in 1998 by developing an econometric model of economic behavior to test the degree of collusion in the market for physician services.

\section{BACKGROUND AND ORGANIZATION OF THE PAPER}

Before the action by the U.S. Government, physician networks and physician independent practice associations (IPA's) were growing at unprecedented rates. HaasWilson and Gaynor (1998) summarized the effects of the physician private practice market by noting that as of 1996, there were 4,000 IPA's with approximately 300 physicians each, up from 1,500 in 1990. Until 1998, many argued that the increase in physician networks was a response to a change in market structure and not due to a strategic attempt to manipulate economic surplus. Prior to an inquiry by the Federal Trade Commission (FTC), it was believed that the market for physician services experienced monopolistic competition, with procedure pricing closely approximating marginal cost. However, the large increase in practices and in practice size, aligned with the rising difficulty to negotiate a fee-for service by insurance companies, caused considerable speculation that the physician marketplace may retain a significant amount of market power. Haas-Wilson and Gaynor (1998) explained the potential effects further by noting that horizontal consolidation by physicians may facilitate two types of collusion: (1) within network collusion and (2) across network collusion. ${ }^{4}$ At one point practice size became so large, that just prior to government intervention the California Healthcare Association predicted there could be as little as three to seven health care networks in the entire state over the course of the next decade.

There are a number of factors that may contribute to physician collusion. Certainly, if physicians observe a highly sensitive demand for their services, or equivalently, if healthcare payers are highly responsive to a change in service price, then physicians may

\footnotetext{
4 The case by the federal government focused on the former, yet the latter is also problematic.
} 
collude and share profits rather than engage in a market game of competition. Moreover, since the current healthcare structure is driven by large third-party payers, physicians may find it more efficient to engage in joint-price negotiations. ${ }^{5} \quad$ The contractual negotiation process of the physician and third-party payer is a costly one. Large networks provide an incentive for the physician to lower their costs, thus resulting in economies of scale with respect to network size. Hence, it is essential to determine whether large physician network size is a reflection of a deliberate attempt to manipulate the competitive pressures of the marketplace, or whether it is merely a byproduct of a powerful third-party payer system.

This paper examines the economic behavior of the physician private practice marketplace and explores the DOJ's claim that physicians possessed a high degree of market power in 1998. The paper is organized as follows: Section 3 provides our theoretical model and Section 4 provides the econometric specification. Section 5 discusses our data source and how the data were constructed. We present our estimation method and our empirical results in Section 6. We conclude in Section 7 with summary comments.

\section{MODEL}

Our model is designed to test the degree of market power within a physician private practice and is consistent with the theoretical framework of the market competition models detailed in Bresnahan (1989). ${ }^{6}$ This theoretical framework has been used in numerous studies. A brief summary includes: Alexander (1994), Graddy (1994), Captain and Sickles (1998), Wolfram (1999), Steen and Salvanes (1999), Roeller and Sickles (2000), Bikker and

\footnotetext{
${ }^{5}$ We note this may influence the efficiency of the contractual negotiation process, but not necessarily economic efficiency as a whole.

${ }^{6}$ See Perloff et al (2007) for similar models.
} 
Haaf (2002), and de Roos (2006). ${ }^{7} \quad$ The recent work by Piller (2007) uses a model reminiscent of Bresnahan (1989) to study the electricity market in California.

Consider the private practice physician as a unit of observation. $N$ physicians produce a differentiated output, $q$, using $i$ inputs, $x=\left(x_{1}, \ldots, x_{n}\right) .{ }^{8}$ We assume that patients possess a given level of demand for physician services and they have the ability to observe and obtain differences in quality, thus yielding asymmetric demand specifications for each individual physician. $\quad$ The market demand function facing physician $k$ is:

$$
y_{k}=y_{k}\left(p_{k}, Q_{k}\right)
$$

where $p_{k}$ is the price faced by the patient for an office visit with physician $k$ and $Q_{k}$ is a vector of variables that shift demand. ${ }^{10}$ Perceived marginal revenue is

$$
P M R=p_{k}+D_{k} y_{k}
$$

where $D_{k}=\frac{\partial p_{k}}{\partial y_{k}} . \quad D_{k}$ is the slope of the inverse demand curve faced by firm $k$. In monopoly equilibrium, $p_{k}-D_{k} y_{k}$ equates marginal revenue. ${ }^{11}$

The objective of the physician is to minimize a cost function of physician and nonphysician inputs, subject to a technological constraint,

$$
\min \sum W_{i} X_{i} \text { subject to } G(Y, X, t) \leq 0
$$

where $G$ represents the transformation function of the production technology. The solution to equation (3) yields the cost function, represented by:

\footnotetext{
7 Our data limitations preclude a forward-looking dynamic model as seen in Alam and Sickles (2000) and Captain, et al. (2007).

${ }^{8}$ We relax the Bresnahan (1989) assumption of homogeneity in output.

9 Those quality differences are experience, gender, and specialty. It has been proposed that malpractice insurance data would be the most appropriate proxy for quality, however that presumes such data are available to all patients for all physicians and patients consult that data prior to an examination.

${ }^{10}$ In addition, $\mathrm{p}_{\mathrm{k}}$ is the price paid to the physician for service and not necessarily the burden directed toward the patient. We discuss this fact in a later section.

11 See Bresnahan (1989) for a full discussion.
} 


$$
C=C(Y, W, T)
$$

In expression (4), $C$ is the summation of practice costs incurred by the physician for his or her production of services. $Y$ represents the measures of output, measured in annual office visits with established patients, new patients, emergency room trips, and hospital rounds. ${ }^{12}$ $W$ are input prices for office rent, non-physician employee payments, and malpractice premiums. $C$ is assumed to be homogeneous of degree one and symmetric in factor prices $(W)$, non-increasing and convex in the levels of the quasi-fixed factor $(T)$, and non-negative and non-decreasing in output $(Y)$.

We specify an equation for physician labor supply, consistent with Escarce and Pauly (1998), which is represented by:

$$
T=T(Y, W)
$$

where $T$ is the annual hours of labor provided by the physician. Output $(Y)$ and input prices $(W)$ are defined in $C$. The specification of $T$ is based on the assumption that the physician is a utility-maximizing agent who solves an optimization problem of net income and leisure. We defer our discussion of the physician labor variable to Section 4.

In theory, the physician chooses the optimal amount of output, where $M C=P M R$ in an oligopolistic economy. Hence, the equilibrium condition is:

$$
C\left(Y_{k}, W_{k}, T_{k}\right)=p_{k}+D_{1}\left(p_{k}, Y_{k}\right) y_{k} \theta
$$

The parameter $\theta$ is a measure of the degree of competition of the physician private practice. Traditionally, if $\theta=0$, then price equals marginal cost and the industry is perfectly

\footnotetext{
12 We use office visits as physician output. There are other measures of physician output that are more comprehensive but less easily observed and measured. For a discussion of these alternatives, health outcomes that can be constructed for these alternatives, and their use in static and intertemporal models of health production see, for example, Sickles and Taubman (1997), Berhman et al. (1998), and Sickles and Yazbeck (1998).
} 
competitive. ${ }^{13}$ If $\theta=1$, then the behavior of the physician is consistent with a Nash game in output or a Cournot oligopoly. Values between 0 and 1 would be considered a form of imperfect competition, while statistically significant values that exceed unity would be evidence of substantial collusion. In a quantity-setting game, the first order conditions for profit-maximization are:

$$
\frac{\partial y_{k}}{\partial p_{k}} p_{k}+y_{k}-\frac{\partial C_{k}}{\partial y_{k}} \frac{\partial y_{k}}{\partial p_{k}}=0
$$

Summing over $N$ physicians $\left(Y=\sum_{k} y_{k}\right)$ :

$$
\frac{\partial Y}{\partial p_{k}} p_{k}+Y-\sum_{k} \frac{\partial C_{k}}{\partial y_{k}} \frac{\partial y_{k}}{\partial p_{k}}=0
$$

Under the assumption of symmetry in costs, the behavioral equation reduces to:

$$
p_{k}=\frac{\partial C_{k}}{\partial y_{k}}-\frac{Y}{\frac{\partial Y}{\partial p}} \theta
$$

or:

$$
p_{k}-M C_{k}=\frac{Y}{\frac{\partial Y}{\partial p}} \theta
$$

where the LHS term " $p_{k}-M C_{k}$ " indicates the mark-up by the physician.

\footnotetext{
${ }^{13}$ It is important to note that when $\theta=0$, price equates marginal cost. However very small values of $\theta$ imply one of two things: either price is very close to marginal cost, or price greatly exceeds marginal cost, but is being offset by a highly inelastic demand. See Bresnahan (1989) or Iwata (1973).
} 


\section{4}

ECONOMETRIC SPECIFICATION

The econometric specification for the cost equation faced by the physician is represented by a non-homothetic generalized Leontief:

$$
\begin{aligned}
& C(Y, W, T)=\alpha_{T} T+\sum_{i=1}^{4}\left(\sum_{j=1}^{3} \sum_{k=1}^{3} \alpha_{i, j, k} W_{j}^{\frac{1}{2}} W_{k}^{\frac{1}{2}}\right) Y_{i}+\sum_{i=1}^{4} \sum_{j=1}^{3} \beta_{i, j} W_{j} Y_{i}+\sum_{i=1}^{4}\left(\sum_{j=1}^{3} \varphi_{i, j} W_{j}\right) Y_{i}^{2} \\
& +\sum_{1 \leq i<l \leq 4} \sum_{j=1}^{3} \varphi_{j, i l} W_{j} Y_{i l}+\sum_{j=1}^{3} \gamma W_{j}+\Gamma+\Psi
\end{aligned}
$$

where $\Gamma$ are practice controls, comprised of dummy variables that indicate whether the physician practices in a metropolitan location and if the physician is board-certified. We include the percentage of patients that pay with Medicaid to control for patient load and a variable for the number of physicians in the practice to control for practice size. $\Psi$ contains four physician-reported dummy variables that describe the practice setting: general practice, medical specialty, surgical specialty, or other. The specification of (8) is advantageous because the cost function maintains desirable theoretical characteristics. The generalized Leontief is homogeneous in input prices by construction and symmetry is imposed prior to estimation. It is a second-order approximation that is locally flexible and imposes no a priori restrictions on the elasticities of factor inputs. The flexible nature of the cost function allows our model to test the degree of scale and scope economies, in addition to the potential non-linearity of marginal costs.

Our specification of the cost function and the treatment of physician labor is deserving of some attention. Reinhardt $(1972,1975)$ was the first to estimate a production function for physician services. Thurston and Libby (2002) revisited this work and found evidence of input substitutabilities. Gaynor and Pauly (1990) provide an in-depth theoretical study behind the physician production process that is expanded upon by Escarce and Pauly (1998). Our model relies heavily upon the theoretical contributions of Escarce and Pauly 
(1998) who show that physician practice cost functions often exhibit an endogeneity bias with respect to physician labor. Most studies treat physician labor as exogenous by including physician labor hours in the cost specification as a right-hand side variable and estimating the cost function in isolation (e.g. Pope and Burge, 1990), thus assuming labor hours as an accurate proxy for the shadow price of physician services. Escarce and Pauly suggest (1998) that such an assumption is spurious, primarily because physician hours and the opportunity cost of physician services is a function of owner status. They further suggest that in theory, a physician utility maximization problem of net income and leisure yields the conditional input demands for income and leisure, thereby yielding the optimal supply of labor to the practice. They estimate a two-equation system: physician labor supply and practice cost. ${ }^{14}$ Our treatment of $T$ is consistent with their contributions.

Escarce and Pauly (1998) specify the cost function as a translog (Christensen, et al. 1978) with Box-Cox transformations on the outputs. The Box-Cox transformations address the issue of physicians reporting zero outputs. ${ }^{15}$ In their illustration, all of the cross-product terms are dropped to preserve degrees of freedom in their limited sample, leading to bias in their estimates and destroying the flexibility of the cost function. ${ }^{16}$ We consider the generalized Leontief cost function proposed by Diewert (1971). The most advantageous feature of the generalized Leontief in a physician services setting is its response to zero outputs. Li and Rosenman (2001) use a multi-product generalized Leontief cost function for their two-product study of the hospital industry. ${ }^{17}$ The Leontief has traditionally been used in a single output setting; however its extension to the multi-output setting has been seen in

\footnotetext{
14 We refer the reader to the Escarce and Pauly (1998) for a detailed derivation.

15 We note these are true zero measures and not missing values.

16 The work by Escarce and Pauly (1998) is primarily theoretical. The authors themselves note that their results are intended to be purely illustrative and not to be viewed as a reliable empirical measure.

17 See Cowing, et al. (1983) and Fischer, et al. (2006) for a discussion on multi-product cost functions in the market for health services.
} 
studies dating back to Hall (1973). We prefer the Leontief over the small-value translog, which has a history of producing erratic measures (Berger, et al. 1999; Weninger, 2003) or the proper quadratic cost function proposed by Roller (1990) and extended by Pulley and Braunstein (1992). Of course the selection of an appropriate approximation to the underlying technology is not an exact science and is often dependent upon the data, as suggested by Guilkey, et al. (1983).

To improve efficiency of the estimation, we derive factor share equations. Differentiating the cost function with respect to each input price yields the unconditional factor demands for the inputs. ${ }^{18}$ The factor demand function for any price $\left(W_{i}\right)$ is:

$$
X_{k}=\frac{\partial C}{\partial W_{k}}=\frac{1}{2} \sum_{i=1}^{4} \sum_{j \neq k} \alpha_{i, j, k} \frac{W_{j}^{\frac{1}{2}}}{W_{k}^{\frac{1}{2}}} Y_{i}+\sum_{i=1}^{4} \sum_{k=1}^{3} \beta_{i, k} Y_{i}+\sum_{i=1}^{4} \varphi_{i} Y_{i}^{2}+\sum_{1 \leq i<l \leq 4} \varphi_{i l} Y_{i l}+\gamma W_{k}
$$

As noted earlier, $T$ is the result of a utility-maximization problem by the physician, yielding the optimal supply of leisure, conditional upon the prices of the nonphysician inputs. Escarce and Pauly (1998) suggest specifying the labor supply equation as a second-order approximation, consistent with the functional form of the cost function. We follow their approach, however we note that physician labor does not face the same theoretical restrictions as the cost function. The physician labor equation is specified as a nonhomothetic generalized Leontief,

$$
\begin{aligned}
& T(Y, W)=\sum_{i=1}^{4}\left(\sum_{j=1}^{3} \sum_{k=1}^{3} \alpha_{i, j, k} W_{j}^{\frac{1}{2}} W_{k}^{\frac{1}{2}}\right) Y_{i}+\sum_{i=1}^{4} \sum_{j=1}^{3} \beta_{i, j} W_{j}+\sum_{i=1}^{4}\left(\sum_{j=1}^{3} \varphi_{i, j} W_{j}\right) Y_{i}{ }^{2} \\
& +\sum_{1 \leq i<l \leq 4} \sum_{j=1}^{3} \varphi_{j, i l} W_{j} Y_{i l}+\sum_{j=1}^{3} \gamma W_{j}+\Gamma+\Psi+\zeta
\end{aligned}
$$

\footnotetext{
18i.e. Shepherd's Lemma
} 
where $\zeta$ are physician-specific heterogeneity controls. $T$ includes a dummy variable for gender and linear and quadratic terms for age and years of experience. We note that the treatment of $T$ results in physician labor being treated as a quasi-fixed factor, yielding a restricted cost function (variable cost function) reminiscent of the specification by Streitweiser and Sickles (1998).

The demand equation is specified linearly with a second-order term in prices to allow curvature:

$$
Y(P)=P+P^{2}+E X P+E X P^{2}+G E N D E R+M E T R O+M E D C A I D+\sum_{i=1}^{4} S P E C_{i}
$$

$E X P$ and $E X P^{2}$ are control variables for the experience of the physician and are entered into the specification in levels. METRO is a dummy variable describing whether the practice is in a metropolitan region. MEDCAID is the percentage of patients that pay via Medicaid and is used to approximate patient-load. $S P E C_{i}$ are binary variables that control for the specialty. Additive error terms are appended to the cost, share, labor, and demand equations.

\section{DATA}

The data for this study is from the 1998 American Medical Association (AMA) Physician Socioeconomic Monitoring Survey (SMS) and the 1998 Geographic Practice Cost Index (GPCI) originally proposed by Zuckerman, et al. (1990). Table I summarizes the data. The SMS is a telephone survey to 3,700 private practice physicians that are members of the AMA and practice in the United States. The SMS is a geographically comprehensive and occupationally detailed survey that provides physician, practice, and demographic characteristics for the physician private practice setting. The cost variable is the sum of nonphysician employee payments, malpractice insurance expenses related to practice, and office expenses. Nonphysician employee payments include secretarial support, nurses, and 
assistants. Malpractice insurance expenses consist of insurance premiums and any additional malpractice costs associated with the practice, such as settlements or legal fees. Office expense is the cost of leasing, renting, or owning the infrastructure that the practice is located in. The office expense variable also includes any rents related to the lease or ownership of technological equipment. The physician labor variable is constructed by multiplying the average hours worked per week, as reported by the physician, by the number of hours practiced in the 1998 calendar year. The same methodology is used to construct the four outputs by multiplying reported weekly outputs by the number of weeks worked in 1998. All demographic and sociological characteristics are reported by the physician and are detailed in the previous section.

The SMS does not contain information on input prices related to the practice or the physician. The GPCI originally by proposed by Zuckerman, et al. (1990) is a Laspeyres index that controls for price fluctuations in health markets by assigning weighted values to inputs. Initially the GPCI contained four subcomponents: office rent, nonphysician wages, malpractice rents, and physician labor, however the GPCI associated with the Medicare Fee Schedule no longer contains a physician labor subcomponent. Pope and Burge (1990) suggest deflating the dependent cost variable by the GPCI to preserve linear homogeneity in prices. However their method is somewhat problematic, since it precludes measurement of share equations, economies of scale and scope, and the interaction of second-order prices. The result is a functional form that does not adhere to economic theory. Escarce and Pauly (1998) use two sub-components of the index; office rent and nonphysician wages, allowing the malpractice subcomponent to be the numeraire and using the physician labor variable as a control for the price of physician labor. Our study uses all three subcomponents of the GPCI for our input prices. The SMS includes detailed descriptions of the location of the 
practice. We use the geographic identifier contained within the SMS to assign the input prices constructed for the GPCI. Since there is reasonable variation in malpractice premiums by location, we include the malpractice subcomponents as a unique measure of price, rather than presume it as the implicit numeraire. The nonphysician employee wage component is constructed by using Census wage data, which is geographically comprehensive and occupationally detailed. To capture the occupation mix of the practice, hourly earnings are weighted by each occupational share of physician expenditures for employees. Office rents are obtained by The U.S. Department of Housing and Urban Development fair market rent for all areas with a Section 8 housing assistance program. Malpractice insurance premiums are based on annual risk and malpractice cost data collected by the Center for Medicare and Medicaid services. ${ }^{19}$

Our sample considers only those physicians who practice at least 20 hours or more a week. Those respondents who spend the majority of their time in a hospital or a school setting are not considered for this study. We control for four categorizations of fields of specialty: general practice, medical subspecialty, surgical subspecialty, and "other" specialties. Our final sample consists of 939 private practice physicians that practice in the lower 48 states.

\section{ESTIMATION AND RESULTS}

The five-equation system consists of the cost equation (8), the physician labor equation (9), two of the three share equations (10), and the demand equation (11)..$^{20}$ The system is estimated via three-stage least squares (3SLS). Table II provides parameter estimates with robust standard errors in parentheses. Escarce and Pauly (1998) have shown that the

\footnotetext{
${ }^{19}$ We refer the reader to Zuckerman, et al. (1990) for a more detailed discussion of the construction of the subcomponents.

${ }^{20}$ One of the share equations is dropped to avoid singularity.
} 
physician characteristics unique to the physician labor equation but excluded from the cost equation, identify the cost function. In our case, those are control variable for the gender of the physician and linear and quadratic controls for age and experience $(\zeta){ }^{21}$ The cost function maintains all of the theoretical properties required by economic theory. Namely, it is linearly homogeneous in prices by construction. Symmetry in factor prices is imposed prior to estimation. The cost function is concave in the three factor prices and in the quasifixed factor. We test the null hypothesis of non-homotheticity of the cost equation and the labor supply equation and reject it at the $1 \%$ level, implying there is significant evidence of price/output interaction. ${ }^{22}$

Table III reports our measures for marginal cost for each of the four outputs. We also report the marginal opportunity cost of an hour of physician labor at the mean. The traditional approach for deriving marginal cost estimates at the mean is to use the parameter estimates from the cost equation and the mean estimates from the data to "back-out" a measure, with standard errors obtained via the delta method. Since our marginal costs are non-linear, we prefer the approach by Li and Rosenman (2001) which consists of using the parameter estimates from the cost equation to obtain a unique marginal cost for each of the observations. We average over the sample and obtain standard errors by dividing the standard deviations by the square root of the sample size. All four of our reported measures of output are significant at the 1\% level. The marginal cost to the physician for an additional visit with an established patient is $\$ 27.23$ and the additional cost of an office visit with a new patient is $\$ 75.97$. Office visits with a new patient typically requires the additional clerical

${ }^{21}$ A regression test of the overidentifying restrictions found that these restrictions could not be rejected $\left(\chi^{2}=8.46 ; \mathrm{p}=0.58\right)$.

${ }^{22}$ The demand for physician services is contained in the cost function and the labor supply equation. Since output price is a function of office visits, we treat the output price variable in the demand equation as endogenous. 
support to process the insurance information, increased secretarial support to develop a case-file, and perhaps most costly is the considerable time required for the physician to review the medical history of the patient. The cost of an emergency room visit at the margin is $\$ 26.91$. An emergency room visit requires less nonphysician labor than traditional office visits, yet may involve considerable opportunity cost to the physician. Our marginal cost measure for scheduled hospital visits is $\$ 16.32$. At first glance, this measure may seem quite low, however scheduled hospital visits involve very little nonphysician inputs and are often aggregate in nature, thus invoking potential economies of scale. It is not uncommon for a physician to visit many patients in a small amount of time, especially for those medical providers in surgical settings.

Since the labor variable and cost variable are entered into the cost specification linearly, the labor coefficient is the marginal cost for an additional hour of physician labor, holding all other factors constant. The labor coefficient is negative, consistent with theory, implying that the physician would have to substitute his or her own labor to lower total practice costs while maintaining the same level of productivity. Our estimate for the marginal cost of an additional hour of physician labor is $\$ 52.87 .^{23}$ This measure can be interpreted as the marginal opportunity cost to the physician for an hour of additional labor.

Table III reports our parameter results from the demand equation and Table IV reports measures for the elasticity of output. We found it critical to select a measure of output that was consistent with all of the physicians in the sample. Many of the physicians in our sample do not spend a great deal of time in a hospital setting and new patient office visits are not necessarily a genuine approximation for physician demand. Therefore, we use the measure for established patient office visits, which also appears as right-hand side

${ }^{23}$ Our point estimates for marginal cost and physician labor are consistent with those of Gunning and Sickles (2007). 
variables in the cost and labor equations, to approximate the demand for physician services. As expected, the demand equation is downward sloping and the coefficient on the linear price term is significant at the 1\% level. Our estimation results report that there is high consumer sensitivity with respect to a change in the price of an office visit for all four specialties. From the consumer perspective this result may seem rather anomalous, since consumers often pay a fixed co-payment and should be almost perfectly inelastic, especially in the case of a single office visit. However, the price variable in the demand equation is the entire price of the office visit, not just the portion paid by the consumer. Therefore the measure of high price sensitivity is most likely an indication of the third-party payers' willingness to substitute existing physicians for less costly physicians when determining which services to make available for their consumers. The point estimates for the elasticities of demand at the mean are all significant at the $1 \%$ level. The average price-elasticities generated from the demand equation range in absolute value from 1.75 to 2.35. Not surprisingly, we find that demand is positively correlated with experience and with practices that are located in metropolitan areas.

We now turn our attention to the competition parameter $(\theta)$, since that is the focus of this analysis. Table IV reports our results. We estimate $(\theta)$ in the same way we derived marginal cost by using the coefficients from the cost and demand equation to obtain unique measures for each observation, and then averaging over the sample. When estimating physicians as a whole and as separate specialties, we strongly reject the null hypothesis of perfect competition, implying that physicians exhibited a form of imperfect competition in $1998(\theta=-1.34)$. Bresnahan (1989) explains that $\theta$ equating to zero is a necessary and sufficient condition for perfect competition. A sufficient condition for a Nash game in output or a Cournot oligopoly is when $\theta=1$. For medical subspecialties, surgical 
subspecialties, and "other" specialties, we fail to reject the hypothesis of a Nash game in quantities at the $1 \%$ level, implying that all specialties other than general practice exhibit behavior consistent with a Cournot oligopoly. We reject the hypothesis of a Nash game in quantities for general physicians, with a point estimate of $\theta=-1.97$ (S.E. $=0.24)$. However, we note that the average price markup over marginal cost is substantial, implying that physicians in general practice maintain a high degree of market power. The average price markup for an office visit with an established patient is approximately $140 \%$ over marginal cost. Our results imply that medical subspecialties, surgical subspecialties and "other" specialties strategically act in a reaction-based form of collusion. However, it appears that general physicians have a much stronger form of market power, as indicated by $\theta$ and their high markups over marginal cost.

We test the null hypothesis of constant returns to scale. Escarce and Pauly find evidence of increasing returns with respect to physician outputs. ${ }^{24}$ The literature in health services is reviewed in Gaynor and Vogt (2000), with Kass (1987) finding little evidence of economies of scale in the market for home health services. Vita (1990) and Cowing and Holtmann (1983) conclude there are scale economies in the market for hospital production. ${ }^{25}$ Economies of scale are measured by inverting the sum of the elasticities of output. Panzar and Willig (1977) have shown that ray economies of scale for a production process with a quasi-fixed factor reduces to,

$$
S C A L E=\frac{C\left(W, Y, T^{*}\right)-t^{*}\left(\frac{\partial C}{\partial T}\right)}{\sum_{i=1}^{4} \frac{\partial C}{\partial Y_{i}} \cdot Y_{i}}
$$

\footnotetext{
${ }^{24}$ In theory, physician private practices exhibit returns based on outputs and practice size. Our study focuses on the former.

${ }^{25}$ See Elbasha and Messonnier (2004) for a summary.
} 
A value $>,<$, or $=$ to unity, implies increasing, decreasing, or constant returns. Due to the high degree of market power in the physician services industry, we suspect high returns to scale. Pauly and Escarce (1998) find a point estimate of 1.67 for the degree of ray economies of scale. Our results yielded a point estimate of $2.76($ S.E. $=0.18)$, indicating very high ray increasing returns to scale. Hence, a $10 \%$ increase in output requires only a $3.62 \%$ increase in practice cost. ${ }^{26}$

Economies of scope can be computed a number of ways. Li and Rosenman (2001) suggest the method by Vita (1990), which indicates that weak cost complementarities are a sufficient condition for economies of scope (i.e. if $\frac{\partial^{2} C}{\partial Y_{i} \partial Y_{j}}<0$ for all $i \neq j$ ). We sum the cross-product coefficients from the cost equation and obtain standard errors via the delta method. Our results yield a point estimate of 0.059 (S.E. 0.045), implying there may be modest scope economies, yet our estimate is unreliable due to the large standard error. Moreover, summing the coefficients of the cross-product terms is simply a sufficient condition for scope economies and does not provide any economic interpretation for the sensitivity that private practices may exhibit with respect to specialization. A more traditional approach is the following:

$$
S C O P E=\frac{\sum_{i=1}^{4} C\left(y_{i}, 0\right)-C(Y)}{C(Y)}
$$

The above expression describes the additional cost to the practice for producing the outputs separately rather than together. Our estimate yields a measure of 15.75 (S.E. $=5.37$ ), implying there is evidence of scope economies. The mean measure for scope economies implies that it would cost the practice $15 \%$ more to produce the four outputs separately than to produce 
them together, however that measure may range as low as $5 \%$ and as high as $25 \%$. We note that our cost function controls for field of specialty. Hence our results imply there is little advantage within a specialty to produce outputs separately, but do not necessarily imply that physician practices cannot exhibit scope economies across specialties.

Allen partial own-price $\left(\varepsilon_{i i}\right)$ and cross-price elasticities $\left(\varepsilon_{i j}\right)$ are reported in Table V (Allen, 1938). Table VI reports Allen-Uzawa partial elasticities of substitution (Uzawa, 1962), defined as $s_{i j}=\frac{\varepsilon_{i j}}{X_{j}}$. Due to symmetry in prices, we report only the upper triangular matrix. The own-price elasticities for nonphysician wages and office rent have the correct sign (-) and are statistically significant at the 1\% level. Nonphysician wages and office rents are relatively inelastic, implying physician private practices are rather unresponsive to a change in price. $^{27}$ The own-price elasticity for malpractice insurance is incorrectly signed $(+)$, but statistically insignificant. The cross-price elasticity for nonphysician wages and office rent is positive and significant, implying physicians may substitute technological or physical capital for human capital. The cross-price elasticities associated with malpractice rent and nonphysician wages is negative, implying that malpractice insurance is a complement to all other inputs in the physician production process. However, we use caution interpreting the malpractice cross-price elasticity with respect to office rent since the point estimates did not achieve significance.

\section{$7 \quad$ Conclusion}

This study examines the degree of collusion in physician private practices for the year 1998. We specify a multi-product cost function, physician labor supply equation, and demand function for physician services. The model treats physician labor supply and output

${ }^{27}$ This result is most likely attributable to long-term contractual obligations on office rent and office equipment, in addition to a high demand for specialized assistants 
price as endogenous. The treatment of physician labor is a direct result of the work by Escarce and Pauly (1998) and Escarce (1996) who show that physician labor may be subject to an endogeneity bias in physician private practice cost functions. We expand upon the generalized conjectural variation framework of Bresnahan (1989). Our estimates reveal that the behavior of medical subspecialties, surgical subspecialties, and "other" subspecialties is consistent with a Cournot oligopoly. In addition, we show that general physicians exhibit a high degree of collusion which may attributed to regional monopolies or patient loyalty. Physicians face a highly sensitive demand with respect to payment from third-party payers, leading them to participate in a form of reaction-based collusion. The majority of the price paid for an office visit is on behalf of a third-party payer with the consumer typically paying a fixed fee in the form of a co-payment. Hence, our findings of high price sensitivity are most likely borne by the third-party payer. The marginal cost estimates that are derived from the cost function suggest that physician services are priced well above marginal cost, reflecting a high degree of market power. Our parameter estimates indicate that physicians enjoy increasing returns to scale within their respective specialty, consistent with the results of Escarce and Pauly (1998). However we find little evidence of scope economies.

1998 was a critical year in the market for physician services. Our empirical results suggest that the investigations by the Federal Trade Commission and charges brought forward by the DOJ are substantiated. In addition, we find that third-party payers are highly sensitive to rising prices, potentially leading to physician collusion. Perhaps the most troubling aspect is the aggregate effect that collusion may have had on the allocation of federal funds. Approximately $17 \%$ of Medicare and Medicaid revenues are paid directly to the physician. After adjusting for inflation with the Consumer Price Index, that figure translates to roughly $\$ 43$ billion dollars in federal outlays in 1998. Based on our price 
markups for an office visit with a general physician, it appears that the impact of collusion in physician private practices may have contributed to almost $\$ 25$ billion dollars in excess spending.

It is imperative to note that the actions by the government did not go unrecognized. The outcome of the investigation by the DOJ led to a number of out of court settlements with the IPA's. The DOJ cites illegal price fixing as their primary motivation for action. The result was a five-year suspension of joint negotiations among large physician networks. Furthermore, the Medicare and Medicaid reimbursement schedule underwent a major renovation in the late 1990 's as an attempt to bring government spending down and to reimburse medical providers at more competitive levels. Nevertheless, the results reported in this paper raise questions as to how the structure of the current reimbursement schedule contributes to inefficient markets. In addition, this study motivates the need for a payment schedule that is based on realized costs and statistical modeling, rather than an examination of accounting data and geographic variation in prices. 


\section{REFERENCES}

Allen R., 1938. Mathematical analysis for economists. (London: Macmillan)

A. Semenick and R. C. Sickles, 2000. Time-series analysis of deregulatory dynamics and technical efficiency: the case of the U.S. airline industry. International Economic Review, 41, 203-218.

Alexander D., 1988. The oligopoly solution tested. Economic Letters, 28, 361-364.

Appelbaum E., 1982. The estimation of the degree of oligopoly power. Journal of Econometrics, 19, 287-299.

Bikker J. and K. Haaf, 2002. Competition and concentration in the EU banking industry. Journal of Banking and Finance, 29, 2191-2214.

Brander J. and A. Zhang, 1990. Market conduct in the airline industry: an empirical investigation. RAND Journal of Economics, 21, 567-583.

Bresnahan T., 1989. Empirical studies of industries with market power. In Schmalensee and R. Willig (eds.) Handbook of Industrial Organization Volume 3 (Amsterdam: North Holland).

Bresnahan T., 1987. Competition and collusion in the American automobile industry: the 1955 price war. Journal of Industrial Economics, 35, 457-482.

Breyer F., 1987. The specification of a hospital cost function: a comment on the recent literature. Journal of Health Economics, 6, 147-157.

Brown D.M., 1988. Do physicians underutilize aides? Journal of Human Resources, 23, 342355.

Christensen L., Jorgensen D., and L. Lau, 1971. Conjugate duality and the transcendental logarithmic production function. Econometrica, 39, 255-256.

Cowing T. and A. Holtmann, 1983. Multi-product short-run hospital cost functions: empirical evidence and policy implications from cross-section data. Southern Economic Journal, 49, 637-653.

Cowing T., A. Holtmann, and S. Powers, 1983. Hospital cost analysis: a survey and evaluation of recent studies. In R. Scheffler (ed.) Advances in Health Economics and Health Services Research Volume 4 (Greenwich: JAI Press).

Diewert W., 1971. An application of the Shephard duality theorem: a generalized Leontief production function. Journal of Political Economy, 79, 481-507. 
Elbasha E. and M. Messonnier, 2004. Cost effectiveness analysis and health care resource allocation: decision rules under variable returns to scale. Health Economics, 13, 21-35.

Ellis, P. and P. Orszag, 2007. The challenge of rising health care costs - a view from the Congressional Budget Office. New England Journal of Medicine, 357, 1793-1795.

Escarce J., 1996. Using physician practice cost functions in payment policy: the problem of endogeneity bias. Inquiry, 33, 66-78.

Escarce J. and M. Pauly, 1998. Physician opportunity costs in physician practice cost functions. Journal of Health Economics, 17, 129-151.

Fischer A., G. Laking, and J. Lord, 2006. Non-linearity in the cost-effectiveness frontier. Health Economics, 15, 565-577.

Gaynor M. and M. Pauly, 1990. Compensation and productive efficiency in partnerships: evidence from medical group practice. Journal of Political Economy, 98, 544-573.

Gaynor M. and W. Vogt. 2000. Antitrust and competition in health care markets. In Handbook of Health Economics, vol. 1B, A. Culyer and J. Newhouse (eds). NorthHolland: Amsterdam, 2000; 1405-1487.

Graddy K., 1994. Testing for imperfect competition at the Fulton Fish Market. RAND Journal of Economics, 26, 75-92.

Guilkey D., C. Lovell, and R.C. Sickles, 1983. A Comparison of the performance of three flexible functional forms. International Economic Review, 24, 591-616.

Gunning T.S. and R.C. Sickles, 2007. A multiproduct cost function for physician private practices. Mimeo, Rice University.

Hall R., 1973. The specification of technology with several kinds of output. The Journal of Political Economy, 81, 878-892.

Haas-Wilson D. and M. Gaynor, 1998. Physician networks and their implications for competition in health care markets. Health Economics, 7, 179-182.

Iwata G., 1974. Measurement of conjectural variations in oligopoly. Econometrica, 42, 949-966.

Kass D., 1987. Economies of scale and scope in the provision of home health services. Journal of Health Economics, 6, 129-146.

Li T. and R. Rosenman, 2001. Estimating hospital costs with a generalized Leontief cost function. Health Economics, 10, 523-538.

Panzar J. and R. Willig, 1977. Economies of scale in multi-output production. Quarterly Journal of Economics, 91, 481-493. 
Perloff J., L. Karp, and A. Golan, 2007. Estimating market power and strategies. (Cambridge: Cambridge University Press)

Pope G. and R. Burge, 1995. The marginal practice cost of physicians' services. The Journal of Socio-economic Planning Science, 29, 1-16.

Pulley L. and Y. Braunstein, 1992. A composite cost function for multi-product firms with an application to economies of scope in banking. Review of Economics and Statistics, 74, 221-230.

Puller S., 2007. Pricing and firm conduct in California's deregulated electricity market. The Review of Economics and Statistics, 89, 75-87.

Reinhardt U., 1972. A production function for physician services. The Review of Economics and Statistics, 54, 55-56.

Reinhardt U., 1975. Physician Productivity and the Demand for Health Manpower. (Cambridge, MA: Ballinger).

Roller L-H., 1990. Proper quadratic cost functions with an application to the bell system. Review of Economics and Statistics, 72, 202-210.

Roller L.-H. and R.C. Sickles, 2000. Capacity and product market competition: measuring market power in a 'puppy-dog' industry. International Journal of Industrial Organization, $18,845-865$.

Rotemberg, J. and G. Saloner, 1986. A supergame-theoretic model of price wars during booms. American Economic Review, 76, 390-407.

Sickles R.C. and M. Streitwieser, 1998. The structure of technology, substitution and productivity in the interstate natural gas transmission industry under the natural gas policy act of 1978. Journal of Applied Econometrics, 13, 377-395.

Sickles R.C. and P. Taubman, 1997. Mortality and morbidity among adults and the elderly, In M. Rosenzweig and O. Stark Handbook of Population and Family Economics. (Amsterdam: North-Holland).

Sickles R.C. and A. Yazbeck, 1998. "On the dynamics of demand for leisure and production of health: evidence from the retirement history survey," Journal of Business and Economic Statistics, 16, 187-197.

Steen F. and K. Salvanes, 1999. Testing for market power using a dynamic oligopoly model. International Journal of Industrial Organization, 17, 147-177.

Thurston N. and A. Libby, 2002. A production function for physician services revisited. The Review of Economics and Statistics, 84, 184-191. 
Uzawa H., 1962. Production functions with constant elasticities of substitution. Review of Economic Studies, 29, 291-299.

Vita M., 1990. Exploring hospital production relationship with flexible functional forms. Journal of Health Economics, 9, 1-21.

Wolfram C., 1999. Measuring duopoly power in the British electricity spot market. American Economic Review, 89, 805-826.

Zuckerman S., Welch W. and G. Pope, 1990. A geographic index of physician practice costs. Journal of Health Economics, 9, 39-69. 


\section{TABLE I}

\begin{tabular}{|c|c|}
\hline & Mean \\
\hline Total Cost & $\$ 270,972$ \\
\hline Annual Labor Hours & 2,336 \\
\hline $\begin{array}{l}\text { Office Visits } \\
\text { (Established Patients) }\end{array}$ & 4,174 \\
\hline Office Visits (New Patients) & 637 \\
\hline ER Visits & 243 \\
\hline Hospital Visits & 693 \\
\hline Nonphysician Price & 1.02 \\
\hline Office Price & 1.07 \\
\hline Malpractice Price & 1.14 \\
\hline Metropolitan & 0.83 \\
\hline Number of Physicians & 3.08 \\
\hline Percentage of Patients paying with Medicaid & 0.12 \\
\hline Board Certified School & 0.79 \\
\hline Experience & 6.81 \\
\hline Age & 2.52 \\
\hline Gender & 0.15 \\
\hline Price of General Visit & 65.30 \\
\hline General Practice & 0.25 \\
\hline Medical Specialty & 0.61 \\
\hline Surgical Specialty & 0.07 \\
\hline Other Specialty & 0.07 \\
\hline
\end{tabular}


TABLE II

\begin{tabular}{|c|c|c|}
\hline & Cost & Physician Labor \\
\hline Labor & $\begin{array}{r}52.89 \\
(35.866)\end{array}$ & - \\
\hline W1 & $\begin{array}{r}-876524.7 \\
(769972)\end{array}$ & $\begin{array}{r}-4016.1 \\
(3633.3)\end{array}$ \\
\hline W2 & $\begin{array}{r}222960 \\
(235936)\end{array}$ & $\begin{array}{r}72.28 \\
(1133.8)\end{array}$ \\
\hline W3 & $\begin{array}{r}9769 \\
(33376) \\
\end{array}$ & $\begin{array}{l}283.45^{*} \\
(154.05)\end{array}$ \\
\hline W1Y1 & $\begin{array}{r}-187.35 \\
(970.2)\end{array}$ & $\begin{array}{r}2.70 \\
(4.62)\end{array}$ \\
\hline W2Y1 & $\begin{array}{r}83.7 \\
(900.5) \\
\end{array}$ & $\begin{array}{r}2.96 \\
(4.29) \\
\end{array}$ \\
\hline W3Y1 & $\begin{array}{r}-5.49 \\
(20.1)\end{array}$ & $\begin{array}{l}-0.054 \\
(0.096) \\
\end{array}$ \\
\hline W1W2Y1 & $\begin{array}{r}120.9 \\
(1866) \\
\end{array}$ & $\begin{array}{r}-5.56 \\
(8.89) \\
\end{array}$ \\
\hline W1W3Y1 & $\begin{array}{c}309.5^{*} \\
(187.4)\end{array}$ & $\begin{array}{r}0.014 \\
(0.896)\end{array}$ \\
\hline W2W3Y1 & $\begin{array}{r}-309.56^{*} \\
(172.2)\end{array}$ & $\begin{array}{r}0.027 \\
(0.825)\end{array}$ \\
\hline W1Y2 & $\begin{array}{r}-9108.9^{*} \\
(4976)\end{array}$ & $\begin{array}{l}-24.22 \\
(23.33)\end{array}$ \\
\hline W2Y2 & $\begin{array}{r}-5810.1 \\
(4369) \\
\end{array}$ & $\begin{array}{l}-17.83 \\
(20.66) \\
\end{array}$ \\
\hline W3Y2 & $\begin{array}{r}23.7 \\
(126)\end{array}$ & $\begin{array}{l}-0.191 \\
(0.604)\end{array}$ \\
\hline W1W2Y2 & $\begin{array}{r}15155^{*} \\
(9302)\end{array}$ & $\begin{array}{r}42.64 \\
(43.79) \\
\end{array}$ \\
\hline W1W3Y2 & $\begin{array}{r}1158.7 \\
(1084.7) \\
\end{array}$ & $\begin{array}{r}3.30 \\
(5.14) \\
\end{array}$ \\
\hline W2W3Y2 & $\begin{array}{r}-1349 \\
(960.2) \\
\end{array}$ & $\begin{array}{r}-3.56 \\
(4.54) \\
\end{array}$ \\
\hline W1Y3 & $\begin{array}{r}11310^{* *} \\
(5113) \\
\end{array}$ & $\begin{array}{r}30.50 \\
(23.73) \\
\end{array}$ \\
\hline W2Y3 & $\begin{array}{l}\text { 8985* } \\
(4818)\end{array}$ & $\begin{array}{r}27.66 \\
(22.52) \\
\end{array}$ \\
\hline W3Y3 & $\begin{array}{r}139.8 \\
(174.2) \\
\end{array}$ & $\begin{array}{l}-0.593 \\
(0.828)\end{array}$ \\
\hline W1W2Y3 & $\begin{array}{r}-20109.1^{* *} \\
(9858)\end{array}$ & $\begin{array}{l}-58.42 \\
(45.90)\end{array}$ \\
\hline IW1W3Y3 & $\begin{array}{r}-308.4 \\
(1273.2) \\
\end{array}$ & $\begin{array}{r}-1.13 \\
(6.09) \\
\end{array}$ \\
\hline W2W3Y3 & $\begin{array}{r}-7.72 \\
(1139) \\
\end{array}$ & $\begin{array}{r}2.18 \\
(5.45) \\
\end{array}$ \\
\hline
\end{tabular}




\begin{tabular}{|c|c|c|}
\hline W1Y4 & $\begin{array}{r}-1786.4 \\
(2205.4)\end{array}$ & $\begin{array}{r}-7.02 \\
(10.46) \\
\end{array}$ \\
\hline W2Y4 & $\begin{array}{l}-767.7 \\
(2121)\end{array}$ & $\begin{array}{r}-6.43 \\
(10.10)\end{array}$ \\
\hline W3Y4 & $\begin{array}{l}-13.7 \\
(72.8) \\
\end{array}$ & $\begin{array}{l}-0.137 \\
(0.348)\end{array}$ \\
\hline W1W2Y4 & $\begin{array}{r}2584.6 \\
(4315) \\
\end{array}$ & $\begin{array}{r}13.83 \\
(20.51) \\
\end{array}$ \\
\hline IW1W3Y4 & $\begin{array}{r}668.3 \\
(536.7) \\
\end{array}$ & $\begin{array}{r}-0.448 \\
(2.56) \\
\end{array}$ \\
\hline IW2W3Y4 & $\begin{array}{r}-644.8 \\
(536.7)\end{array}$ & $\begin{array}{l}0.596 \\
(2.13)\end{array}$ \\
\hline W1Y1Y1 & $\begin{array}{r}-0.023 \\
(0.015)\end{array}$ & $\begin{array}{r}-0.00006 \\
(0.00007)\end{array}$ \\
\hline W2Y1Y1 & $\begin{array}{r}0.013 \\
(0.016) \\
\end{array}$ & $\begin{array}{r}0.00011 \\
(0.00008) \\
\end{array}$ \\
\hline W3Y1Y1 & $\begin{array}{r}0.009 \\
(0.009)\end{array}$ & $\begin{array}{r}-0.00005 \\
(0.00004)\end{array}$ \\
\hline W1Y2Y2 & $\begin{array}{c}-0.174 \\
(0.178)\end{array}$ & $\begin{array}{r}-0.00088 \\
(0.00084)\end{array}$ \\
\hline W2Y2Y2 & $\begin{array}{r}0.124 \\
(0.248) \\
\end{array}$ & $\begin{array}{r}0.00106 \\
(0.00117)\end{array}$ \\
\hline W3Y2Y2 & $\begin{array}{r}0.010 \\
(0.121) \\
\end{array}$ & $\begin{array}{r}-0.00022 \\
(0.00058)\end{array}$ \\
\hline W1Y3Y3 & $\begin{array}{r}-0.059 \\
(0.343)\end{array}$ & $\begin{array}{r}-0.00212 \\
(0.0016)\end{array}$ \\
\hline W2Y3Y3 & $\begin{array}{r}0.131 \\
(0.484)\end{array}$ & $\begin{array}{r}0.00228 \\
(0.00227)\end{array}$ \\
\hline W3Y3Y3 & $\begin{array}{r}-0.076 \\
(0.178)\end{array}$ & $\begin{array}{c}-0.00071 \\
(0.00085)\end{array}$ \\
\hline W1Y4Y4 & $\begin{array}{r}0.069 \\
(0.063) \\
\end{array}$ & $\begin{array}{l}0.00032 \\
(0.0003)\end{array}$ \\
\hline W2Y4Y4 & $\begin{array}{r}-0.081 \\
(0.088) \\
\end{array}$ & $\begin{array}{r}-0.00041 \\
(0.00042) \\
\end{array}$ \\
\hline IW3Y4Y4 & $\begin{array}{r}0.007 \\
(0.037) \\
\end{array}$ & $\begin{array}{r}0.00007 \\
(0.00018)\end{array}$ \\
\hline W1Y1Y2 & $\begin{array}{r}0.141^{* * *} \\
(0.054)\end{array}$ & $\begin{array}{r}0.00022 \\
(0.00026)\end{array}$ \\
\hline W1Y1Y3 & $\begin{array}{l}-0.057 \\
(0.055)\end{array}$ & $\begin{array}{c}-0.0004 \\
(0.0003)\end{array}$ \\
\hline W1Y1Y4 & $\begin{array}{r}-0.004 \\
(0.034)\end{array}$ & $\begin{array}{c}0.0003^{* *} \\
(0.00015)\end{array}$ \\
\hline W1Y2Y3 & $\begin{array}{r}-0.155 \\
(0.341)\end{array}$ & $\begin{array}{r}0.0037^{* *} \\
(0.0015)\end{array}$ \\
\hline W1Y2Y4 & $\begin{array}{l}0.330^{*} \\
(0.195)\end{array}$ & $\begin{array}{c}-0.0012 \\
(0.0009)\end{array}$ \\
\hline
\end{tabular}




\begin{tabular}{|c|c|c|}
\hline W1Y3Y4 & $\begin{array}{r}0.082 \\
(0.119)\end{array}$ & $\begin{array}{r}0.00043 \\
(0.00056)\end{array}$ \\
\hline W2Y1Y2 & $\begin{array}{r}-0.129 * * * \\
(0.050)\end{array}$ & $\begin{array}{r}-0.00024 \\
(0.00024)\end{array}$ \\
\hline W2Y1Y3 & $\begin{array}{r}0.054 \\
(0.050) \\
\end{array}$ & $\begin{array}{l}0.000354 \\
(0.00023)\end{array}$ \\
\hline W2Y1Y4 & $\begin{array}{r}0.003 \\
(0.031) \\
\end{array}$ & $\begin{array}{r}-0.0003^{* *} \\
(0.00014)\end{array}$ \\
\hline W2Y2Y3 & $\begin{array}{r}0.218 \\
(0.306)\end{array}$ & $\begin{array}{r}-0.0035^{* * *} \\
(0.00133)\end{array}$ \\
\hline W2Y2Y4 & $\begin{array}{r}-0.392^{* *} \\
(0.175)\end{array}$ & $\begin{array}{c}0.00103 \\
(0.0008)\end{array}$ \\
\hline W2Y3Y4 & $\begin{array}{r}-0.053 \\
(0.122) \\
\end{array}$ & $\begin{array}{r}-0.00042 \\
(0.00058)\end{array}$ \\
\hline W3Y1Y2 & $\begin{array}{r}0.002 \\
(0.006)\end{array}$ & $\begin{array}{r}0.00002 \\
(0.00003)\end{array}$ \\
\hline W3Y1Y3 & $\begin{array}{r}-0.005 \\
(0.008)\end{array}$ & $\begin{array}{l}0.000001 \\
(0.00038)\end{array}$ \\
\hline W3Y1Y4 & $\begin{array}{r}0.003 \\
(0.005) \\
\end{array}$ & $\begin{array}{r}-0.000003 \\
(0.0002)\end{array}$ \\
\hline W3Y2Y3 & $\begin{array}{r}0.004 \\
(0.036) \\
\end{array}$ & $\begin{array}{r}0.00018 \\
(0.00017)\end{array}$ \\
\hline W3Y2Y4 & $\begin{array}{r}0.023 \\
(0.025) \\
\end{array}$ & $\begin{array}{r}0.00018 \\
(0.00012)\end{array}$ \\
\hline W3Y3Y4 & $\begin{array}{r}-0.007 \\
(0.024)\end{array}$ & $\begin{array}{r}-0.00003 \\
(0.0001)\end{array}$ \\
\hline SPEC1 & $\begin{array}{r}84785 \\
(586191)\end{array}$ & $\begin{array}{l}-38.94 \\
(87.69)\end{array}$ \\
\hline SPEC2 & $\begin{array}{l}965699 * \\
(588051)\end{array}$ & $\begin{array}{r}78.60 \\
(80.87) \\
\end{array}$ \\
\hline SPEC3 & $\begin{array}{r}886480 \\
(587972)\end{array}$ & $\begin{array}{r}96.84 \\
(109.1)\end{array}$ \\
\hline SPEC4 & $\begin{array}{r}888689 \\
(587972)\end{array}$ & \\
\hline METRO & $\begin{array}{l}-24222 \\
(15921)\end{array}$ & $\begin{array}{r}2.76 \\
(76.4) \\
\end{array}$ \\
\hline DOCNUM & $\begin{array}{l}1838.3 \\
(1515)\end{array}$ & $\begin{array}{r}-8.71 \\
(7.13)\end{array}$ \\
\hline MEDCAD & $\begin{array}{r}-117.7 \\
(310)\end{array}$ & $\begin{array}{r}-0.803 \\
(1.48)\end{array}$ \\
\hline CERT & $\begin{array}{r}2112.3 \\
(11082)\end{array}$ & $\begin{array}{l}-97.04 * \\
(53.62)\end{array}$ \\
\hline AGE & - & $\begin{array}{r}124.13 \\
(119.77)\end{array}$ \\
\hline AGESQ & - & $\begin{array}{r}-29.39 \\
(22.13)\end{array}$ \\
\hline
\end{tabular}




\begin{tabular}{|l|r|r|}
\hline EXP & - & -194.15 \\
& - & $(305.4)$ \\
\hline EXPSQ & - & 16.97 \\
& - & $(22.27)$ \\
\hline GENDER & -0.799 \\
& - & $(57.51)$ \\
\hline CONSTANT & & $5869.2 * *$ \\
& & $(2866.9)$ \\
\hline
\end{tabular}

Standard errors appear in parentheses.

${ }^{*} \mathrm{p}<0.10$

$* * \mathrm{p}<0.05$

$* * * \mathrm{p}<0.01$

TABLE III

\begin{tabular}{|l|r|}
\hline & Demand Equation \\
\hline Price & $-94.95^{* *}$ \\
& $(44.6)$ \\
\hline Price squared & -0.109 \\
& $(0.271)$ \\
\hline Experience & 650.5 \\
\hline Experience Squared & $(1177.7)$ \\
\hline Gender & -39.17 \\
& $(83.46)$ \\
\hline Medicaid & -142.3 \\
& $(307.2)$ \\
\hline Metropolitan & -9.66 \\
& $(7.85)$ \\
\hline Specialty 1 & 356.5 \\
& $(300.49)$ \\
\hline Specialty 2 & $-1285^{* * *}$ \\
& $(450)$ \\
\hline Specialty 3 & -182.7 \\
& $(421.03)$ \\
\hline Specialty 4 & -55.14 \\
& $(596.2)$ \\
\hline Constant & - \\
& $6821^{*}$ \\
& $(4197.2)$ \\
\hline
\end{tabular}


TABLE IV

(Marginal Costs at the Mean)

\begin{tabular}{|l|c|}
\hline \multicolumn{1}{|c|}{ Outputs } & Marginal Cost \\
\hline Established Patient Office Visit & $\$ 27.23^{* * *}$ \\
& $(1.54)$ \\
\hline New Patient Office Visit & $\$ 75.97^{* * *}$ \\
& $(3.26)$ \\
\hline Emergency Room Visit & $\$ 26.91^{* * *}$ \\
& $(2.76)$ \\
\hline Hospital Visit & $\$ 16.32^{* * *}$ \\
& $(1.79)$ \\
\hline Opportunity Cost of an hour of & $\$ 52.87$ \\
Physician Labor & $(32.57)$ \\
\hline
\end{tabular}

Standard errors appear in parentheses

$* \mathrm{p}<0.10$

$* * \mathrm{p}<0.05$

$* * * \mathrm{p}<0.01$

\section{TABLE V}

\section{Demand Elasticities and Competition Parameter}

\begin{tabular}{|l|c|c|}
\hline \multicolumn{1}{|c|}{ Specialties } & Elasticity of Demand & Theta \\
\hline General Practice & $-2.35^{* * *}$ & $-1.87^{* * *}$ \\
& $(0.20)$ & $(0.24)$ \\
\hline Medical Specialties & $-1.76^{* * *}$ & $-1.19^{* * *}$ \\
& $(0.25)$ & $(0.32)$ \\
\hline Surgical Specialties & $-1.75^{* * *}$ & $-1.04^{* * *}$ \\
& $(0.20)$ & $(0.19)$ \\
\hline Other & $-1.75^{* * *}$ & $-1.11^{* * *}$ \\
& $(0.26)$ & $(0.23)$ \\
\hline
\end{tabular}

Standard errors appear in parentheses.

${ }^{*} \mathrm{p}<0.10$

$* * \mathrm{p}<0.05$

$* * * \mathrm{p}<0.01$ 
TABLE VI

OWN-Price ANd Cross-Price Elasticities

\begin{tabular}{|l|c|c|c|}
\hline \multicolumn{1}{|c|}{ INPUTS } & $\begin{array}{c}\text { NONPHYSICIAN } \\
\text { WAGES }\end{array}$ & OFFICE RENT & MALPRACTICE \\
\hline $\begin{array}{l}\text { NONPHYSICIAN } \\
\text { WAGES }\end{array}$ & $-0.132^{* * *}$ & $0.224^{* * *}$ & $0.058^{* *}$ \\
\hline OFFICE RENT & 0.052 & $-0.282^{* * *}$ & 0.080 \\
\hline MALPRACTICE & 1.578 & -1.794 & 0.106 \\
\hline
\end{tabular}

$*_{\mathrm{p}}<0.10$

$* * \mathrm{p}<0.05$

$* * * \mathrm{p}<0.01$

TABLE VII

Allen-Uzawa OWn-Price and Cross-Price Elasticities of Substitution

\begin{tabular}{|l|c|c|c|}
\hline \multicolumn{1}{|c|}{ INPUTS } & $\begin{array}{c}\text { NONPHYSICIAN } \\
\text { WAGES }\end{array}$ & OFFICE RENT & MALPRACTICE \\
\hline $\begin{array}{l}\text { NONPHYSICIAN } \\
\text { WAGES }\end{array}$ & $-0.880^{* * *}$ & $0.593^{* * *}$ & $0.628^{* *}$ \\
\hline OFFICE RENT & - & $-0.746^{* * *}$ & 0.866 \\
\hline MALPRACTICE & - & - & 1.147 \\
\hline
\end{tabular}

${ }^{*} \mathrm{p}<0.10$

$* * \mathrm{p}<0.05$

$* * * \mathrm{p}<0.01$ 